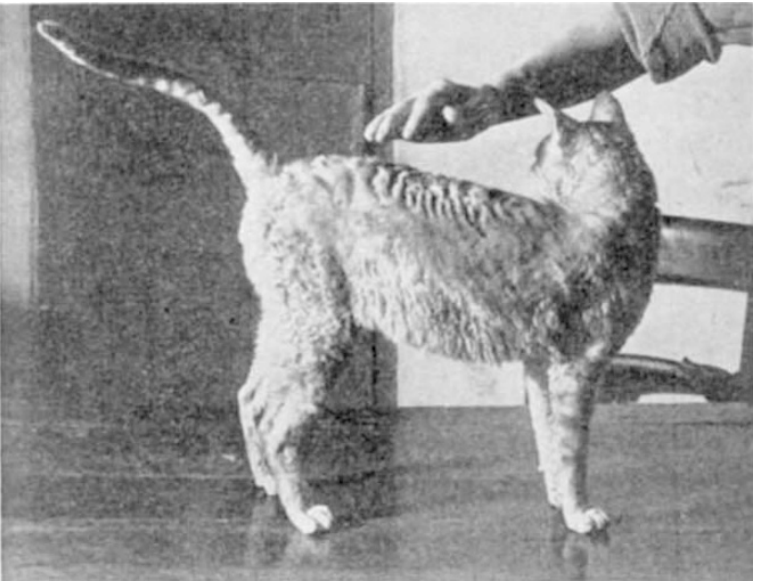

Original male mutant of 'rex' coat-type in the cat

the rex rabbit ; the whiskers are curled. The original mutant (a male which also carries the sex-linked gene for yellow hair colour) has been mated to his tortoiseshell mother. Seven kittens have been produced so far, of which three have been rex. So the condition is inherited; but it is not yet possible to tell whether as a recessive or a dominant.

It is hoped to publish further details later.

A. C. JUDE

3 Hill Vjew Road, Mapperley, Notts. May 23.

${ }^{1}$ Griuneberg, H., "The Genetics of the Mouse" (Martinus Nijhoff, 1952 ).

2 Grüneberg, H., "Animal Genetics and Medicine”' (Hamish Hamilton, 1947 )

\section{Inhibition of Superovulation in the Rabbit}

ThE horse pituitary extract $A P .118 . B$ induces superovulation in albino does at 12 weeks of age, provided the animals are fed at a high level from birth. Treatment consists of six subcutaneous injections of this pituitary extract at 12-hr. intervals, followed by an intravenous injection of 25 I.U. prolan $12 \mathrm{hr}$. later. When this treatment was repeated in the same does at 28-day intervals, in 95 per cent of the experiments the ovarian response was poor and ovulation did not occur. Ovulation did occur at sexual maturity, but only the normal number of ova was shed.

Parkes $^{1}$ found that a 10-day as opposed to a 5-day treatment with horse pituitary extract caused a decrease in ovarian stimulation in adult albino does, which suggested that the formation of antibodies might be very rapid.

On the basis of these observations, it was thought possible that the transfer of plasma from a pituitary- treated doe to an untreated one might inhibit ovarian response when the latter was afterwards treated with the same preparation. The results of experiments to test this possibility (see table) suggest that citrated plasma from a doe treated with the horse pituitary extract $A P .118 . B$ has this inhibiting power.

This work, which was carried out during the tenure of an Agricultural Research Council studentsbip, will be described in detail elsewhere. I wish to thank Dr. A. S. Parkes for making available the preparation $A P .118 . B$, and Dr. John Hammond and Lord Rothschild for advice and encouragement.

Agricultural Research Council

C. E. Anams

Unit of Animal Reproduction,

Huntingdon Road, Cambridge. Jan. 22.

${ }^{2}$ Parkes, A. S., J. Endocrinol., 3, 268 (1942).

\section{Polyspermy in Mammals}

Polyspermy - the entry of more than one sperm into the vitellus at fertilization-is commonly regarded as a pathological process in mammals, with the implication that it leads to early degeneration of the embryo, and this opinion has been expressed by such authorities as Lams ${ }^{1}$, Wilson ${ }^{2}$, and Hartman ${ }^{3}$. In fact, very little is known concerning polyspermy in mammals, and data on its incidence or consequences are lacking. A study has therefore been made of polyspermy in the rat and rabbit, and a brief account of the results is presented in this communication. A full report is being prepared for publication elsewhere.

In the initial experiments, adult virgin female rats wero permitted to mate under normal colony conditions by being placed with males in the afternoon and left with them overnight. Mated rats were recognized by their having a copulation plug when examined the following morning. Sixty-eight mated rats obtained in this way were killed during the day and the eggs recovered for examination in the fresh state with a phase-contrast microscope. These rats provided a total of 627 eggs, of which 614 (97.9 per cent) had been penetrated by sperms. Nine of the penetrated eggs, or 1.5 per cent, were polyspermic ; in each of these, one extra sperm had entered ths vitellus. The polyspermic eggs were in various stagee of fertilization when examined; in two eggs the sperm heads were undergoing metamorphosis and pronuclei had not yet formed, but both midpieces and both acrosomes could be distinguished as they lay in the egg cytoplasm. The remaining polyspermic eggs were in different stages of pronuclear growth, and in each one the extra sperm midpiece and the extra pronucleus were clearly seen. It was noticeable that the two male pronuclei were almost identical in size and appearance.

\begin{tabular}{|c|c|c|c|c|c|c|c|}
\hline Rabbit No. & 1 & 2 & 3 & 4 & 5 & 6 & $i$ \\
\hline & $\begin{array}{c}\mathrm{P} \text { and } \mathrm{M} \\
(84,112,140, \\
168)\end{array}$ & $\begin{array}{c}\mathrm{P} \text { and } \mathrm{M} \\
(112,140,168, \\
196,360)\end{array}$ & & $\begin{array}{l}\mathrm{P} \text { and } \mathrm{M}(81) \\
\text { (No ovulation) }\end{array}$ & & & \\
\hline Treatment & $\begin{array}{l}\text { Plasma to } \\
\text { No. } 7 \text { (322) }\end{array}$ & $\begin{array}{l}\text { Plasma to } \\
\text { No. } 3(367)\end{array}$ & $\begin{array}{l}\text { Plasma from } \\
\text { No. } 2(110)\end{array}$ & & $\begin{array}{l}\text { Plasma to } \\
\text { No. } 6(100)\end{array}$ & $\begin{array}{l}\text { Plasma from } \\
\text { No. } 5 \text { (83) }\end{array}$ & $\begin{array}{l}\text { Plasma from } \\
\text { No. } 1(83)\end{array}$ \\
\hline $\begin{array}{l}\text { Result of final } \\
\text { treatment } \\
\text { (number of } \\
\text { ovulations) }\end{array}$ & $\mathrm{P}_{(338)}^{\text {and } \mathrm{M}}$ & & $\underset{(116)}{P \text { and } M}$ & $\underset{(116)}{\mathrm{P} \text { and }} \mathrm{M}$ & $P \underset{(116)}{P}$ and $M$ & $\mathrm{P} \underset{(99)}{\text { and }} \mathrm{M}$ & $\mathrm{P} \underset{\text { (99) }}{\text { and }} \mathrm{M}$ \\
\hline Less than 10 & Yes & Yes & Yes & No & No & No & No \\
\hline More than 20 & No & No & No & No & Yes & Yes & No \\
\hline
\end{tabular}

P, treatment with $A P .118 . R ; \mathrm{M}$, mating. Age in days at the beginning of each treatment is given in brackets. 